Rabaska

Revue d'ethnologie de l'Amérique française

\title{
Simonne Voyer (1913-2013)
}

\section{Gynette Tremblay}

Volume 12, 2014

URI : https://id.erudit.org/iderudit/1026799ar

DOI : https://doi.org/10.7202/1026799ar

Aller au sommaire du numéro

Éditeur(s)

Société québécoise d'ethnologie

ISSN

1703-7433 (imprimé)

1916-7350 (numérique)

Découvrir la revue

Citer ce document

Tremblay, G. (2014). Simonne Voyer (1913-2013). Rabaska, 12, $226-227$.

https://doi.org/10.7202/1026799ar

Ce document est protégé par la loi sur le droit d'auteur. L'utilisation des services d'Érudit (y compris la reproduction) est assujettie à sa politique d'utilisation que vous pouvez consulter en ligne.

https://apropos.erudit.org/fr/usagers/politique-dutilisation/ 


\section{Nécrologie}

\section{Simonne Voyer (1913-2013)}

Le 8 octobre 2013, Simonne Voyer décédait à l'âge de 100 ans. Femme curieuse et passionnée, elle poursuivit parallèlement à sa carrière d'enseignante et de conseillère pédagogique, qu'elle exerça pendant 28 ans à la Commission des écoles catholiques de Montréal, celle d'ethnologue, spécialiste de la danse traditionnelle.

Son intérêt pour ce secteur de recherche trouve sa source dans un constat qu'elle fait lors de son passage à l'Université Columbia (New-York) :

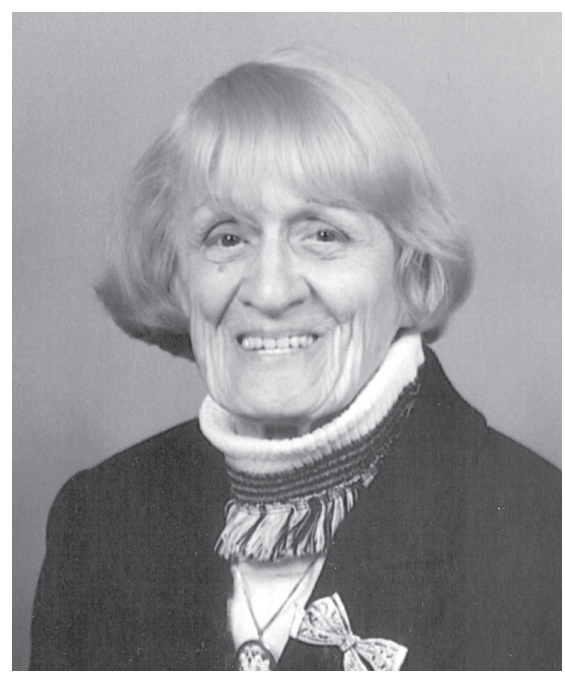

Lors d'un spectacle qui clôturait mes études de maîtrise en 1949, j'ai eu l'occasion de voir des étudiants étrangers qui présentaient les danses de leurs pays. Ce fut un véritable choc parce que, moi, je ne pouvais même pas leur parler des danses de chez-nous. À Rosemont, on ne dansait pas de quadrilles. J'ai donc décidé que, de retour au Québec, j'allais les apprendre pour revenir présenter ce qui se faisait chez-nous, dans nos campagnes. J'ignorais alors qu'il s'agissait d'un défi de taille.

Dès 1950, Simonne Voyer se joint à l'équipe des Archives de folklore de l'Université Laval fondées par Luc Lacourcière. Sur les conseils de Madeleine Doyon-Ferland, elle entreprend ce qui va devenir son terrain de prédilection, l'étude des danses traditionnelles. Désormais initiée aux techniques d'enquête ethnographique, elle parcourra le Québec et l'Acadie pour noter minutieusement plus d'une centaine de cotillons, quadrilles, contredanses, etc. Sa connaissance des danses l'amènera à chorégraphier les extraits exécutés par les personnages du tout premier téléroman diffusé à Radio-Canada : Cap-aux-sorciers. Son travail de recherche, sur la gigue et la contredanse en 
particulier, fera l'objet de publications, de communications et surtout d'un doctorat qu'elle obtiendra à l'âge de 71 ans ; intitulé La Danse traditionnelle au Canada français : quadrilles et cotillons, l'ouvrage est publié aux Presses de l'Université Laval. Cette chercheuse infatigable entreprendra, à l'âge de 85 ans, des études postdoctorales qui l'amèneront à consulter les documents inédits conservés dans des bibliothèques aux États-Unis et en Europe. Encore en juin 2003, elle présentait à titre de conférencière invitée au New Orleans International Ballet Conference, événement international organisé dans le cadre du bicentenaire de la Louisiane, une communication qui surprendra les spécialistes, surtout étatsuniens, qui découvrent que les danses telles qu'enseignées par les maîtres à danser européens étaient connues par ceux et celles qui fréquentaient les salons au temps de la Nouvelle-France.

Simonne Voyer laisse par son travail acharné et son amour inconditionnel de la danse, un héritage inestimable dans la constitution d'un répertoire de danses qui seraient passées à jamais dans l'oubli. Ses publications retracent l'histoire, établissent l'apport des immigrants et démontrent le lien indissociable entre la pratique de la danse et la vie sociale dans laquelle elle évolue. Soucieuse de respecter les danses telles que recueillies auprès d'informateurs avec qui elle avait tissé des liens sincères, elle a développé une technique de notation chorégraphique basée sur le diagramme et établi une terminologie qui les décrit avec clarté et précision. Madame Simonne Voyer laisse certes le souvenir impérissable d'une femme rigoureuse, travaillante, coquette et pleine d'entrain, mais aussi, dans le cœur des membres de sa famille et de ses amis, la marque d'une amitié indéfectible ${ }^{1}$.

Gynette TREMBlay Université Laval

1. Voir le portrait présenté dans un volume antérieur : Jocelyne Mathieu, « Simonne Voyer, à la découverte des danses traditionnelles en Amérique française ", Rabaska, vol. 7, 2009, p. 95-102. 